Gut, 1985, 26, 4-7

Liver and biliary

\title{
Infection with the delta agent in children
}

\author{
P FARCI, C BARBERA, C NAVONE, F BORTOLOTTI, P VAJRO, \\ N CAPORASO, A VEGNENTE, N ANSALDI, M RIZZETTO, \\ $P$ TOLENTINO, ${ }^{*}$ AND R CALZIA
}

From the 1st Medical Clinic, University of Cagliari, 2nd Pediatric Clinic, University of Torino, Institute for Infectious Diseases, University of Genova, Institute of Clinical Medicine, University of Padova, Dept of Clinical Pediatrics, 2nd School of Medicine, University of Napoli, Institute of Pediatrics, 2nd School of Medicine, University of Napoli, and the Division of Gastroenterology, Molinette, Torino, Italy

SUMmARY Serological evidence of infection with the hepatitis B virus associated delta agent $(\delta)$ was found in 34 of 270 Italian children with HBsAg-positive liver disease. In different histological forms of chronic HBsAg hepatitis the prevalence of $\delta$ infection increased in parallel with the activity of the disease and was maximal in children with cirrhosis. During two to seven years of follow up the hepatitis deteriorated in $38 \%$ of the 34 patients with $\delta$ infection and ameliorated only in $9 \%$. By contrast the disease usually ran a mild course in the $236 \delta$-negative carriers of HBsAg, with remission in $55 \%$ of these children and deterioration in only $7 \%$. The outcome of chronic hepatitis associated with $\delta$ infection was not influenced by treatment with steroids and azathioprine. Chronic $\delta$ infection in children is usually accompanied by serious liver disease, that has a tendency to progress and is unresponsive to conventional immunosuppressive treatment.

Evidence has accumulated from clinical studies in adults that chronic infection with the hepatitis $B$ surface antigen ( $\mathrm{HBsAg}$ ) - associated delta agent $(\delta)$ is usually accompanied by serious liver disease. ${ }^{1}$

To establish the prevalence and pathogenic role of $\delta$ infection in children, 270 pediatric patients with HBsAg-positive liver disease followed during the years 1975-1982 in Italy were examined for serological evidence of chronic $\delta$ infection. The features of $\delta$-positive children were compared with those of $\delta$-negative chronic type B liver disease of infancy (1-14 years).

\section{Methods}

\section{PATIENTS}

The study included 270 children that were submitted to liver biopsy on clinical indications of chronic liver disease; all had been positive for serum HBsAg for at least six months before liver biopsy.

One hundred and sixty-five patients were studied in Genoa, 60 in Naples, 27 in Padua and 18 in Turin. One hundred and seventy two of them were of southern and 98 of northern Italian origin. One

Address for correspondence: Professor Renata Calzia, Clinica Malattie Infettive Universita di Genova, Via 5 Maggio 39, 16147 Genova, Italy.

Received for publication 5 April 1984

- Deceased 22 June, 1983 hundred and eighty two were boys, 88 girls and the age varied from $1-14$ years (mean $7 \cdot 4$ years). After the initial histological diagnosis all the patients were followed up for two to seven years (mean 3.6 years) with periodic examinations and liver functions tests; a second or more liver biopsies were performed when clinically indicated.

Liver histology was interpreted according to the criteria of De Groote. ${ }^{2}$ Chronic delta infection was diagnosed on the finding of antibody to delta antigen (anti- $\delta$ ) in serum collected at the time of the original histological diagnosis and on persistence of this antibody in subsequent sera collected during follow up. One hundred and sixty patients received treatment (chemotherapy) according to protocols unrelated to the presence or absence of delta infection. Therapy consisted of a combination of prednisone $(1 \mathrm{mg} / \mathrm{kg} /$ day $)$ and azathioprine $(1 \mathrm{mg} /$ $\mathrm{kg} /$ day) and was prolonged for not less than eight months and up to three years.

At follow up, improvement of the liver disease was usually inferred from persistent decrease or normalisation of aminotransferase value with no increase or with normalisation of IgG values; in a minority of cases it was determined from amelioration of the liver biopsy findings. Lack of variation or deterioration of the liver disease was usually determined on unchanged or worsened 
biopsy findings and in a minority of patients was inferred from persistence of raised aminotransferase value or from increase of aminotransferase value (three-fold above the baseline established at clinical presentation) accompanied or not by an increase in the IgG level. Overall the follow up was based on histology in 134 children and on assessment of liver function test in the other 136 .

\section{ASSAYS}

HBsAg, $\mathrm{HBe}$ antigen ( $\mathrm{HBeAg}$ ) and antibody (anti$\mathrm{HBe}$ ) were measured with commercial radioimmunoassay (Ausria, HBe Kit, Abbott Laboratory, North Chicago, Illinois).

Anti- $\delta$ was measured and titred with a blocking radioimmunoassay previously described ${ }^{3}$ - Titres of 1:5000 or above were considered indicative of chronic delta infection. ${ }^{3}$

Statistical analysis was performed by the $\chi^{2}$ test.

\section{Results}

Several different forms of chronic hepatitis were observed at histology in the initial liver biopsies obtained from the 270 children; chronic lobular hepatitis in three, chronic persistent hepatitis in 100 , chronic active hepatitis without cirrhosis in 158 and cirrhosis in nine.

Anti- $\delta$ was found at titres of $1: 5000$ or above in the initial serum sample of 34 of the 270 children $(12.5 \%)$ and persisted at high titres $\left(1: 5000\right.$ to $\left.1: 10^{5}\right)$ in the blood specimens collected thereafter from each positive patient. Twenty six of the $\delta$-positive patients were of southern and eight of northern Italian heritage; 27 were boys and seven were girls.

The age specific percentage of $\mathrm{HBsAg}$-carrier children with delta relative to $\mathrm{HBsAg-carrier}$ children without delta is given in the Figure.

None of the 236 patients initially negative for anti- $\delta$ developed the antibody during the follow-up.

The prevalence of anti- $\delta$ in the different forms of chronic HBsAg-positive hepatitis is shown in Table 1. The antibody was found in none of the chronic lobular hepatitis, in $6 \%$ of chronic persistent hepatitis, in $15 \%$ of chronic active hepatitis without cirrhosis and in $44 \%$ of cirrhosis. The prevalence of anti- $\delta$ in cirrhosis or in cirrhosis plus chronic active hepatitis without cirrhosis was significantly higher than in the other forms of chronic hepatitis.

At first examination, 181 patients were positive for serum $\mathrm{HBeAg}(67 \%)$ and 73 were positive for anti-HBe $(27 \%) ; 16$ patients were negative for both reactivities. Ten of the 34 patients positive for anti- $\delta$ had serum $\mathrm{HBeAg}(29 \%)$ and 21 had anti-HBe $(71 \%)$; three were negative for both reactivities. The prevalence of anti- $\delta$ in children with anti-HBe

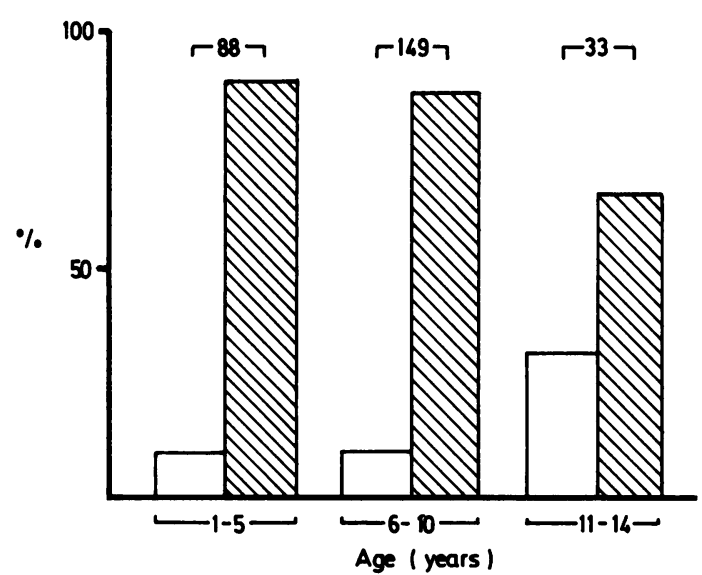

Figure Age-specific percentage of delta-positive ( $\square$ ) to delta-negative (\$) chronic HBsAg hepatitis of children. A total of 270 children were examined, divided in age 1-5 (88 children), 6-10 (149 children) and 11-14 (33 children).

$(21 / 73=29 \%)$ was significantly higher than in children with $\mathrm{HBeAg}(10 / 181=5.5 \%)(\mathrm{p}<0.001)$. The interim course of the liver disease was rated as improved in 129 of the 236 children (55\%) without $\delta$-infection, unvaried in $91(38.5 \%)$ and worsened in $16(7 \%)$. It was rated as improved in three of the 34 (9\%) children with $\delta$-infection, unvaried in 18 $(53 \%)$ and worsened in $13(38 \%)$ (Table 2).

The overall rate of improvement in $\delta$-negative children was significantly higher than the improvement rate in $\delta$-positive patients $(p<0.001)$; in contrast, the rate of deterioration was significantly higher in $\delta$-positive than in $\delta$-negative children $(\mathrm{p}<0.001)$.

The histological follow up in children submitted to repeat liver biopsies is shown in Table 3. In the

Table 1 Prevalence of anti- $\delta$ in 270 children with chronic HBsAg-positive liver disease, divided for histological diagnosis

\begin{tabular}{lllll}
\hline \multirow{5}{*}{ Total } & \multicolumn{4}{l}{ Histological diagnosis } \\
\cline { 2 - 5 } CLH & $C P H$ & $C A H$ & $C I R$ \\
\hline 270 & 3 & 100 & 158 & 9 \\
anti-8-positive $=34$ & 0 & 6 & 24 & 4 \\
& \multicolumn{5}{c}{$\mathrm{p}<0.001$} \\
& \multicolumn{5}{c}{$\mathrm{p}<0.01$} \\
\hline
\end{tabular}

$\mathrm{CLH}=$ chronic lobular hepatitis, $\mathrm{CPH}=$ chronic persistent hepatitis, $\mathbf{C A H}=$ chronic active hepatitis, $\mathrm{CIR}=$ cirrhosis. 
Table 2 Outcome of chronic HBsAg liver disease in 270 children followed-up for 2-7 years (mean 3.6 years), divided in positive and negative for anti- $\delta$

\begin{tabular}{|c|c|c|c|c|}
\hline & No & Improved & Unvaried & Worsened \\
\hline Positive for anti- $\delta$ & 34 & $\begin{array}{c}3 \\
(9 \%) \\
\downarrow \\
\mathrm{p}<0.001\end{array}$ & $\begin{array}{l}18 \\
(53 \%)\end{array}$ & $\begin{array}{l}13 \\
(38 \%) \\
\downarrow \\
\mathrm{p}<0.001\end{array}$ \\
\hline Negative for anti- $\delta$ & 236 & $\begin{array}{l}129 \\
(55 \%)\end{array}$ & $\begin{array}{l}91 \\
(38 \cdot 5 \%)\end{array}$ & $\begin{array}{l}16 \\
(7 \%)\end{array}$ \\
\hline
\end{tabular}

$\delta$-positive group, four of the five patients with an initial diagnosis of chronic persistent hepatitis developed chronic active hepatitis without cirrhosis and six of those with initial chronic active hepatitis without cirrhosis developed a more active disease or cirrhosis; histology did not change or ameliorated in five of the 15 patients $(33 \%)$ in this group. In the $\delta$-negative group, seven of the 34 patients with an initial diagnosis of chronic persistent hepatitis developed chronic active hepatitis without cirrhosis and five of those with initial chronic active hepatitis without cirrhosis developed a more active disease or cirrhosis; histology did not change or ameliorated in 107 of the 119 patients (90\%) in this group.

There was no significant difference in outcome of $\delta$-positive liver disease among treated and untreated patients (Table 4). Of the 21 treated, the disease remitted in $2(9 \%)$, deteriorated in nine $(43 \%)$ and remained unvaried in $10(48 \%)$. Of the 13 untreated, it remitted in one $(8 \%)$, remained unvaried in eight $(61 \%)$ and deteriorated in four $(31 \%)$.

None of the children cleared HBsAg from serum during the follow up and none of the 10 patients with

Table 3 Histological follow-up in 15 8-positive and 119 ठ-negative children with chronic HBsAg positive hepatitis

\begin{tabular}{|c|c|c|}
\hline & Initial & Final \\
\hline$\delta$-positive (15 children) & $\left\{\begin{array}{l}\mathrm{CPH}=5 \\
\mathrm{CAH}=10\end{array}\right.$ & $\left\{\begin{array}{l}\mathrm{CPH}=1 \\
\mathrm{CAH}=4 \\
\mathrm{CPH}=1 \\
\mathrm{CAH}_{+}=4 \\
\mathrm{CAH}=3\end{array}\right.$ \\
\hline$\delta$-negative (119 children) & $\left\{\begin{array}{l}\mathrm{CPH}=34 \\
\mathrm{CAH}=85\end{array}\right.$ & $\begin{array}{l}\mathrm{CPH}=27 \\
\mathrm{CAH}=7 \\
\mathrm{CPH}=62 \\
\mathrm{CAH}=18 \\
\mathrm{CAH}_{+}=2 \\
\mathrm{CIR}=3\end{array}$ \\
\hline
\end{tabular}

$\mathrm{CLH}=$ chronic lobular hepatitis, $\mathrm{CPH}=$ chronic persistent hepatitis, $\mathrm{CAH}=$ chronic active hepatitis $(+=$ severe inflammation), CIR = cirrhosis.
Table 4 Outcome of chronic HBsAg-positive liver disease associated with $\delta$ infection in treated ${ }^{*}$ and untreated children

\begin{tabular}{lllll}
\hline & No & Improved & Unvaried & Worsened \\
\hline Treated & 21 & 2 & 10 & 9 \\
& & $(9 \%)$ & $(48 \%)$ & $(43 \%)$ \\
Untreated & 13 & 1 & 8 & 4 \\
& & $(8 \%)$ & $(61 \%)$ & $(31 \%)$ \\
\hline
\end{tabular}

* Steroids and azathioprine

anti- $\delta$ that were initially positive for $\mathrm{HBeAg}$ seroconverted to anti-HBe.

\section{Discussion}

The prevalence of chronic $\delta$ infection in Italian children with HBsAg-positive liver disease was lower $(12.5 \%)$ than reported in HBsAg-positive adults from the same population $(14-51 \%) ;{ }^{4}$ in the paediatric population it was also lower in younger than older patients.

This is consonant with the demonstration that vertical transmission of delta from mother to newborn occurs very seldom ${ }^{5}$ and with the hypothesis that chronic $\delta$ infection is acquired through superinfection of carriers of $\mathrm{HBsAg},{ }^{6}$ a mechanism implying that the risk is proportional to the duration of HBs antigenaemia and age of the carrier.

The percentage of $\delta$ infection in the different histological forms of chronic hepatitis increased in parallel with the activity of the disease and was maximal in the few children with cirrhosis, confirming the association between $\delta$ infection and serious liver morbidity that has repeatedly emerged from studies in adults. 178

The different course of the HBsAg-positive hepatitis in children with and without $\delta$ infection provides evidence for the direct and major role played by $\delta$ in the pathogenesis of $\mathrm{HBs} \mathrm{Ag}$-positive liver disease.

During the follow up, the clinical and histological features of the liver disease deteriorated in a consistent proportion of the children with $\delta$ infection (38\%) and improved only in a minority of these patients $(9 \%)$. The outcome was not influenced by treatment with steroids or azathioprine, which proved ineffective in preventing progression of the disease. In contrast, in children without $\delta$ infection the course of hepatitis was usually mild, with remission in a high percentage (55\%) and worsening only in a few (7\%).

As previously shown in adults, ${ }^{1}$ a correlation 
between chronic $\delta$ infection and presence of anti$\mathrm{HBe}$ was also observed in the children. In contrast to the prvalence of anti- $\mathrm{HBe}$ in the adult $\mathrm{HBsAg}$ population, however, $\mathrm{HBeAg}$ was predominant in our children, suggesting that segregation of the anti-HBe characteristic with $\delta$ infection is not by chance but presumably linked with a biological predisposition conferred by this state to develop chronic $\delta$ infection.

As anti-HBe identifies a late phase of HBV infection that follows the early stage marked by the presence of serum $\mathrm{HBeAg},{ }^{910}$ one can contend that the severe liver disease observed in children with $\delta$ depends on the longer duration of HBV infection rather than on the pathogenic effect of the defective virus. The course of the hepatitis, however, was remarkably benign in the majority of our infants with anti-HBe but without delta, and the variable length of $\mathrm{HBV}$ infection before clinical presentation is minimised in young patients.

It thus appears that superimposed $\delta$ infection modifies profoundly the natural history of chronic HBsAg-positive hepatitis in infancy, converting a usually mild disease into a severe hepatitis with propensity to progression.

In view of the uncertain prognosis of chronic $\delta$ hepatitis in children, recognition of this form is of major clinical importance since it carries a consistent risk of progressive disease.

The following have collaborated in this study: B Ciravegna, M G Marazzi, Genova. C Sacchetti, A Moiraghi, Torino. R Di Toro, C Del Vecchio Blanco, M Coltorti, Napoli. P Cadrobbi, C Crivellaro, A Berteggia, and G Realdi, Padova.

\section{References}

1 Rizzetto M, Verme G, Recchia S et al. Chronic HBsAg Hepatitis with intrahepatic expression of delta antigen. An active and progressive disease unresponsive to immunosuppressive treatment. Ann Intern Med 1983; 98: 437-41.

2 De Groote J, Desmet VJ, Gedick P et al. A classification of chronic hepatitis. Lancet 1968; 2: 626-8.

3 Rizzetto M, Shih JW-K, Gocke DJ et al. Incidence and significance of antibodies to delta antigen in hepatitis B virus infection. Lancet 1979; 2: 986-90.

4 Smedile A, Lavarini C, Aricò S et al. Epidemiological patterns of infection with the hepatitis B virus associated delta $(\delta)$ agent in Italy. Am J Epidemiol 1983; 117: 223-9.

5 Zanetti A, Ferroni P, Magliano E et al. Vertical transmission of the Hepatitis $B$ Virus and of the HBV-associated delta agent from mothers to offspring in Northern Italy. J Med Virol 1982; 9: 139-49.

6 Smedile A, Dentico P, Zanetti A et al. Infection with the HBV associated delta $(\delta)$ agent in HBsAg carriers. Gastroenterology 1981; 81: 992-7.

7 Govindarajan S, Kanel GC, Peters RL. Prevalence of $\delta$ antibody among chronic Hepatitis B virus infected patients in the Los Angeles area: its correlation with liver biopsy diagnosis. Gastroenterology, 1983; 85: 160-2.

8 Weller IVD, Karajiannis P, Lok ASF et al. The significance of delta agent infection in chronic hepatitis B viral infection in Great Britain. Gut 1983; 24: 1061-63.

9 Hoofnagle JH. Chronic type B Hepatitis. Gastroenterology 1983; 84: 422-4.

10 Bortolotti F, Cadrobbi P, Crivellaro C et al. Changes in the hepatitis B e Antigen/Antibody System in children with chronic hepatitis B virus infection. J Pediatr 1983; 103: 718-22. 